INTERNATIONAL MONETARY FUND
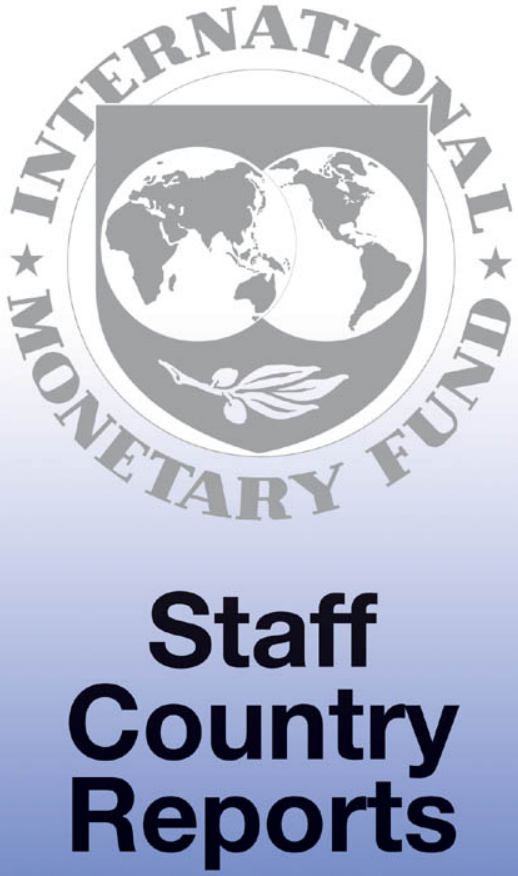


\section{The Gambia: Poverty Reduction Strategy Paper-Joint Staff Advisory Note}

The attached Joint Staff Advisory Note (JSAN) on the Poverty Reduction Strategy Paper for The Gambia, prepared jointly by the staffs of the World Bank and the IMF, was distributed with the member country's Poverty Reduction Strategy Paper (PRSP) to the Executive Boards of the two institutions. The objective of the JSAN is to provide focused, frank, and constructive feedback to the country on progress in implementing its Poverty Reduction Strategy (PRS).

To assist the IMF in evaluating the publication policy, reader comments are invited and may be sent by e-mail to publicationpolicy@imf.org.

Copies of this report are available to the public from

International Monetary Fund • Publication Services $70019^{\text {th }}$ Street, N.W. • Washington, D.C. 20431

Telephone: (202) 623-7430 • Telefax: (202) 623-7201

E-mail: publications@imf.org •Internet: http://www.imf.org

\section{International Monetary Fund \\ Washington, D.C.}


This page intentionally left blank

CInternational Monetary Fund. Not for Redistribution 
INTERNATIONAL MONETARY FUND

AND

INTERNATIONAL DEVELOPMENT ASSOCIATION

THE GAMBIA

Joint Staff Advisory Note On the Poverty Reduction Strategy PaPer

Prepared by the Staffs of the International Monetary Fund and the International Development Association

Approved by Michael Nowak and Carlo Cottarelli (IMF)

and Obiageli Ezekwesili (IDA)

June 4, 2007

\section{OVERVIEW}

\section{The Gambian authorities have prepared their second PRSP covering the years}

2007 to 2011. The first PRSP covered the years 2002 to 2005, and was presented to the Boards of the International Development Association and the International Monetary Fund in July 2002. The overall strategic priorities remain the same in the second PRSP:

(i) macroeconomic stability and effective public resource management; (ii) promotion of propoor growth and employment through private sector development; (iii) improved basic social services; (iv) strengthened local communities and civil society organizations (CSOs); and (v) mainstreamed multisectoral programs on gender, environment, nutrition, and population. The second PRSP is in three volumes: the main text, a needs assessment, and an action plan. The phasing of expenditures and related financing needs have been planned with the objective to make progress towards achieving the Millennium Development Goals (MDGs) by 2015. The Annual Progress Reports (APRs) for the first PRSP indicated that implementation progress has been mixed. Education and health sectors experienced improvements, but programs in other areas experienced delays, the macroeconomic targets were not met, and the share of poverty-related expenditures have been lower than targeted.

\section{The second PRSP emphasizes that its preparation was done in a highly} participatory and consultative manner. Stakeholder consultative workshops and focus group discussions were held with representatives of the public and private sectors and civil society. Consultations reached down to the level of local communities. Participatory Poverty Assessments, Community Scorecards, and "budget games" were incorporated into the preparatory process. The preparation was coordinated by the Strategy for Poverty Alleviation 
Coordinating Office (SPACO) in the Department of State for Finance and Economic Affairs (DOSFEA). Non Government Organizations (NGOs) directly participated in the drafting of the PRSP document. In the future, the newly created National Planning Commission (NPC) will assume overall responsibility for the PRSP process, while also coordinating with SPACO and the new Aid Coordination Unit (ACU) currently being established in DOSFEA. In the staffs' view, it is important to clarify the responsibilities of these new agencies to avoid overlaps, ensure consistency with the Paris Declaration on aid effectiveness, and allocate adequate resources for operational effectiveness. Given resource constraints, organizational consolidation could be an option to consider. Also, the staffs recommend further institutionalizing multisectoral and participatory monitoring arrangements such as the Inter-Departmental Steering Committee and the Poverty Reduction Dialogue Forum in order to make them more effective.

\section{Poverty remains a significant challenge for the country. The PRSP reports a} poverty headcount ratio of 61 percent, based on the 2003 household expenditure survey. Furthermore, poverty is substantially higher for households which are larger, headed by females, and working in the agriculture and fishing industries. There are large regional variations. The staffs recommend that the poverty analysis be further developed in order to better understand poverty developments over time, disparities across subregions, socioeconomic variations, and the impact of public policies on the poor, particularly reforms of the groundnut sector which employs many of the poor.

\section{Strategic Priorities, Risks and Challenges}

\section{The key to macroeconomic stability is sustaining recent policy successes. The} macroeconomic environment has improved considerably in recent years and a new Poverty Reduction and Growth Facility (PRGF) arrangement with the Fund was approved in February 2007. The staffs agree with the major macroeconomic objectives of the second PRSP: (i) consolidate the recent gains in macroeconomic stability; (ii) reduce the domestic debt down to a sustainable path; and (iii) implement reforms in revenue and expenditure management. A major priority is to maintain fiscal discipline in order to reduce the domestic debt. This is expected to reduce domestic interest rates and allow increased lending to the private sector. Maintaining a stable macroeconomic environment is one of the HIPC Completion Point triggers. The staffs recommend giving priority to the implementation of the policy reforms needed for reaching the Completion Point as this will free up significant amounts of additional resources for poverty reducing activities, particularly since the country is also eligible for the Multilateral Debt Relief Initiative (MDRI). The staffs also recommend updating the macroeconomic framework in the PRSP with the latest available data. This can be done in the next APR. Revised official data and recent economic developments suggest a significantly higher outlook for the GDP growth rate than originally anticipated. This largely explains the differences in projections in the PRSP and other more recent programs such as the PRGF. 
5. The staffs recommend that initiatives in the agriculture sector be further focused on private sector promotion. The PRSP indicates that most of the poor are farmers in rural areas, particularly groundnut farmers, and that agricultural productivity has stagnated in recent years. The staffs recommend further refining the specificity of PRSP priority programs for improving agricultural productivity, consolidating donor projects, and exploring ways to improve the effectiveness of public and private funding for the sector through a coherent and robust policy environment and public private partnership. Development of the sector will likely require a multisectoral approach which encompasses agricultural development, employment creation, and improvement of health, education, and physical infrastructure. In order for the government to play a supportive role to private sector development, the staffs recommend that the authorities facilitate, rather than directly intervene, in agricultural production and input supply. This could be achieved in the groundnut sector by promoting private sector participation in the government owned groundnut plants as the initial steps towards improving efficiency of the subsector and eventual divestment of the groundnut plants, a HIPC completion point trigger. The authorities are currently preparing a groundnut sector restructuring strategy on this basis.

\section{The staffs recommend that the authorities prepare a detailed program for} improving the investment climate based on ongoing assessments. The latest Doing Business survey indicates that the country ranks relatively poorly at 113 out of 175 countries. The PRSP outlines programs to strengthen the infrastructure, provide investment incentive schemes, and streamline legal and administrative procedures. Legal reforms have been slow and intermittent, but there has been some recent progress in operationalizing an Alternative Dispute Resolution (ADR) system. Preliminary results from the currently ongoing Investment Climate Assessment (ICA) indicate that the supply of electricity is considered the most critical constraint, in addition to access and costs of credit, access to land, and taxes. The ICA complements the ongoing Diagnostic Trade Integration Study (DTIS) which will identify constraints and recommend actions to promote growth and diversification at the level of subsectors, particularly groundnuts, horticulture, fisheries and tourism. More detailed subsectoral programs thus developed can compensate for the lack of policy specificity in the second PRSP, particularly with respect to the groundnut and fisheries subsectors. The staffs recommend that these subsectoral programs be linked with the ongoing initiative to establish a Business Park (Free Trade Zone) and that the various investment incentive schemes be reviewed. The staffs also recommend that the authorities articulate a comprehensive strategy for developing the financial markets and facilitating credit to the private sector, and link this strategy to sectoral programs.

\section{The PRSP emphasizes that strengthening the National Water and Electricity}

Company (NAWEC) is critical for private sector development. The authorities indicated that it has taken measures to improve the operations of the public utility by bringing in private management. The staffs recommend that the authorities improve the operations of NAWEC by: (i) strengthening the institutional oversight arrangement for NAWEC, possibly 
by creating a separate agency responsible for the energy portfolio; (ii) improving the contractual arrangement for private management, including by incorporating specific performance targets and addressing possible conflict of interest issues; and (iii) strengthening the legal regulatory environment, including by building the capacity and enhancing the mandate of the Public Utilities Regulatory Authority (PURA). International private investors would need assurance of a robust and independent regulatory environment in order to invest in the country.

\section{There are new sets of challenges to maintaining the relative success in the social}

sectors. The PRSP indicates that the next challenges are to improve education outcomes and the quality of schooling, and putting greater emphasis on primary services and preventive care. Enrolment rates compare favorably to other countries in West Africa, but the high failure rates in standardized tests indicate that the quality of education is still poor. The staffs believe that the keys to improving health services is to further decentralize resources and responsibilities to regional units, particularly to the Divisional Health Teams, and to develop and expand community-based services. The staffs recommend that the authorities adopt a more transparent and competitive drug procurement process in order to address poor availability of drugs. The staffs also recommend that the authorities prioritize strengthening human resources in the social sectors, including through greater allocation of personnel to rural areas through incentive programs.

\section{The PRSP supports greater decentralization and expansion of social} development funds in order to better target public services for the poor. Given that there has been limited progress in implementing the Local Government Act in 2002, the staffs recommend the preparation of a country-owned implementation plan and a sensitization program which would create momentum. The staffs also recommend clarifying the role of the Poverty Reduction Fund, a comprehensive social development fund, with respect to other existing social development funds.

\section{The staffs recommend continued implementation of the country's HIV/AIDS} programs. The latest data from 2005 indicate that the infection has stabilized at 1.1 percent (HIV-1) and 0.6 percent (HIV-2). The PRSP indicates that the main challenges will be to sustain the successes achieved so far by maintaining the existing multisectoral approach against HIV/AIDS which is focused on intensive promotion of family planning methods and social marketing of condoms, particularly by targeting core transmitters. There has been relatively good progress in improving malnutrition and expanding vaccination. The staffs recommend a more comprehensive assessment of national programs on population and the environment.

\section{The increase in female enrolment rate is one of the major PRSP successes. A} significant contributing factor has been a girls scholarship program. The staffs recommend an education outreach program for the general population for changing traditional views that limit opportunities for women. It will also be critical to mainstream gender issues into 
development policies, including with respect to access to credit, markets and employment opportunities.

\section{Slippages in macroeconomic policies continue to be one of the most significant} risks in implementing the second PRSP. This is a critical lesson learned from the previous PRSP, during which fiscal indiscipline and loose monetary policies undermined PRSP implementation. The experiences of the first PRSP are particularly relevant because the strategic orientation of the second PRSP is largely similar to the first one. It will be critical to continue strengthening public expenditure management, internal controls of $\mathrm{CBG}$, and fiscal and monetary coordination in order to prevent macroeconomic slippages. The other major risks are the low capacity of the public sector, and governance shortcomings. These risks are being addressed through the ongoing civil service reform exercise, and initiatives to strengthen management of public resources, the investment climate and the independence of the CBG. It will also be important that the development partners maintain an open dialogue with the authorities on the importance of strengthening governance.

\section{KEY IMPLEMENTATION ISSUES}

13. Monitoring would be facilitated by greater results orientation. Unlike the first PRSP, the second PRSP significantly improves results orientation by including an implementation action plan which outlines costed priority activities according to major areas of the strategy. The staffs recommend further developing the action plan by refining target outcomes and outputs in the action plan, and strengthening their linkages with program activities and inputs. Many of the outcome and output indicators could be more clearly defined and quantified. Donor coordination would be facilitated if the action plan indicated which donors are active in which strategic areas. Past JSAN recommendations on strengthening monitoring are still relevant: (i) producing APRs in a timelier manner; (ii) more fully utilizing APRs to make strategic adjustments to the PRSP; and (iii) better integrating APRs into the budget process. In particular, the last APR was produced for 2004.

\section{Strengthened monitoring will also depend on improved data quality, availability} and analysis. The PRSP refers to the recent establishment of the semi-autonomous Gambia Bureau of Statistics (GBOS). A new Statistics Act (2005) was enacted, a Statistical Master Plan prepared, and a Statistics Council constituted. In order for the restructuring process to be effective, the staffs recommend that the authorities provide adequate resources to GBOS, ensure its semi-independence, but also hold GBOS accountable for improved data quality and availability. In particular, economic statistics need to be improved. Newly collected data sets and related reports, such as the household survey, poverty analysis and the economic census, should be widely disseminated in a timely manner.

15. PRSP priorities can be further integrated into the government budget process. Progress has been made in the form of budget codes which identify PRSP related 
expenditures. The PRSP emphasizes the adoption of a Medium-Term Expenditure Framework (MTEF) as a means to further deepen the integration of PRSP priorities with the budget, but progress has so far been slow. The adoption of a MTEF will likely require active leadership by DOSFEA in collaboration with NPC, improved reliability of future projections of sectoral resource allocations, and the preparation of coherent and costed sector strategies based on explicitly defined outcomes and outputs. Existing Public Expenditure Reviews (PERs), including the sectoral PERs for the education, health, agriculture and road sectors, can form the basis for the preparation of a MTEF. In addition, the authorities have initiated efforts to establish Sector Wide Approaches (SWAps) in the education and health sectors. The resulting country-owned comprehensive sector development programs can be used to incorporate PRSP priorities.

\section{The staffs recommend that the authorities further refine the estimate of the}

financing gap in the PRSP. The financing gap is defined as the total cost of activities identified in the action plan, minus projected government and donor contributions and savings from Heavily Indebted Poor Countries (HIPC) debt relief. The country reached HIPC Decision Point in December 2000, but has yet to reach Completion Point. The staffs recommend improving the estimates of the financing gap by: (i) updating the estimated size of the funding from the government, donors and debt relief; (ii) identifying activities that are already funded from ongoing or imminent donor projects in order to estimate the need for additional funding; and (iii) identifying activities as either capital or current expenditures, and ensuring that the recurrent cost implications of capital expenditures are adequately addressed. Certain activities, such as the civil service reform, still need to be further elaborated and costed. The estimated funding gap is quite large; on an annual basis, it is slightly larger than the total average external grants and loans that the country currently receives. Therefore, the staffs recommend that the authorities consider further prioritization.

\section{The staffs agree with the PRSP that there is a need for a comprehensive civil} service reform. Building capacity of the public sector is both a PRSP objective and a key determinant of its successful implementation. The authorities have been experiencing difficulties recruiting and retaining qualified personnel, and improving organizational and individual performance. Improving civil service performance is a critical basis for sustaining earlier gains achieved in education and health sectors as well as generally improving public service delivery. The authorities are in the process of developing a civil service reform program with support from the donors. The design of the program will be based on an assessment of public sector capacity. The staffs recommend that the reforms focus on improving pay and employment management, public sector capacity and governance. The compensation package should be analyzed comprehensively and linked to performance. It will be critical to address any existing governance shortcomings, such as the lack of transparency, accountability and rule of law. Sustained political commitment for the implementation of the reform program will be essential. 


\section{The staffs recommend that the authorities focus on local capacity building in} order to sustain ongoing public financial management (PFM) reforms. The PRSP refers to the Integrated Financial Management Information System (IFMIS) as an integral part of its strategy to strengthen public expenditure management and monitor PRSP related expenditures. The first phase of IFMIS was launched in January 2007. Its sustainability will depend on building a knowledgeable local team which is properly resourced. IFMIS currently does not cover expenditures from donor projects. Given the significant share of these expenditures in public spending, their eventual incorporation in IFMIS would significantly improve PFM. There has been some progress in reducing the backlog of public accounts, and it will be critical to continue making progress. With respect to improving management of revenue collection, the PRSP cites the central role of the newly established semi-autonomous Gambia Revenue Authority (GRA). The GRA will be sustainable only if its recurrent costs are adequately funded. A possible source of increased funding for GRA is performance incentives linked to revenue collection. The staffs commend the first ever taxpayer survey conducted in 2005, and recommend that it be highly publicized, and actions be taken to address shortcomings identified in the survey.

19. Strengthened governance remains a priority for the PRSP process. It will be critical to sustain ongoing efforts to strengthen public expenditure management, public procurement, the investment climate, and internal controls at the Central Bank. The second PRSP recognizes past governance shortcomings at the Central Bank of The Gambia (CBG), and the damaging role it had on the economy. Governance shortcomings included:

(i) inadequate internal controls, particularly for international reserves; (ii) questionable audit practices; and (iii) lack of independence reflected in government interference in $\mathrm{CBG}$ operations and limited control over credit to the government. It will also be critical for the PRSP process to be open, transparent and participatory in order to promote country ownership and a government that is responsive to the needs of the poor. In this respect, free dissemination of information and an independent media are critical.

\section{CONCLUSION AND ISSUES FOR DISCUSSION}

\section{The staffs recommend further institutionalization of the PRSP process as a} comprehensive approach to overall public policy-making. Going beyond simply aggregating sector policies and project initiatives, the PRSP process could be used as a forum to prioritize and sequence policies and activities. Prioritization is needed not only because resources are limited and the funding gap significant, but also because the absorptive capacity of the public sector is limited. Roundtable discussions could be used for further prioritization once estimates of the financing gap have been refined. Monitoring of PRSP related expenditures is expected to be further regularized through IFMIS generated reports. The staffs recommend refining the PRSP budget codes which are the basis for the PRSP expenditure reports, and also strengthening their linkages to program activities and target outputs and outcomes. The newly created National Planning Commission (NPC) is expected 
to take a leadership role in preparing and implementing PRSP programs and integrating them with the budget. It will be important to smoothly manage the transition period until NPC is adequately resourced such that it is able to fully carry out its mandate. Close collaboration with DOSFEA and the line ministries will also be critical.

21. Do Directors agree with staffs' conclusions for: (i) areas in which further analysis or adjustments to the PRSP are needed; (ii) improving its implementation; and (iii) possible risks. 